\title{
Maternal and Health System Predictors of Preeclampsia among Pregnant Women Attending Health Care Facilities in Lusaka, Zambia: A Retrospective Cohort Study
}

\author{
Pamela Mwansa ${ }^{1 *}$, Hope Mwansa ${ }^{2}$, Ubong Akpan ${ }^{3}$ \\ ${ }^{1}$ Department of Public Health, University of Lusaka, Lusaka, Zambia \\ ${ }^{2}$ Department of Environmental Health, Lusaka Apex Medical University, Lusaka, Zambia \\ ${ }^{3}$ Nigeria Field Epidemiology and Laboratory Training Program, Abuja, Nigeria
}

\begin{abstract}
Preeclampsia (PE) is the leading cause of maternal and perinatal morbidity/mortality. A study in Lusaka estimated Preeclampsia/Eclampsia prevalence at $18.9 \%$. The aim of the study was to determine the health system and maternal predictors of preeclampsia among pregnant women attending public health facilities (HF) in Lusaka, Zambia. This is a 12months retrospective cohort study. Records of 770 pregnant women during antenatal care between January to December 2020 from five HFs in Lusaka were reviewed and classified into with or without PE. The risk factors for PE were abstracted from the records. Descriptive analysis and inferential statistics were determined. The respondents were aged 18-40years with mean age of 27.09 years and SD \pm 5.1 . Age 25- 32 years accounted for 344 (45\%), Married 250 (82\%), 346 (45\%) had secondary school education and 293 (38\%) had parity of 2. Significant differences were observed in the administration of magnesium sulphate and oxygen for severe preeclampsia $(p=0.001)$ and anti-hypertensive for eclampsia $(p<0.05)$. Knowledge gaps in the diagnosis and management of pre-eclampsia were identified. Multivariate analysis revealed woman's age ( $a O R=0.326,95 \%$ CI: 0.0024-0.8231), education aOR=0.128, 95\% CI: 0.00121-0.0323) and a good nutritional diet aOR=0.109, 95\% CI: 0.0393-0.4639) were independent predator of PE. Predictors of PE amongst pregnant women were having preeclampsia in the previous pregnancy, having parity of three or more, and knowledge gaps in the diagnosis and management of PE were found. We recommend refresher training on detection and management of $P E$ among health workers attending to pregnant women.
\end{abstract}

Keywords: Health system, Lusaka, maternal factors, Preeclampsia, Pregnant women.

\section{Introduction}

Hypertensive disorders of pregnancy are a leading cause of maternal morbidity and mortality in low and middle-income countries across the world. They contribute up to $14 \%$ (approximately 42,000) of all maternal deaths globally, with the majority of morbidity and mortality associated with preeclampsia. $[1,2,3$, 4]. Both preeclampsia and eclampsia are widely known to be associated with adverse maternal and foetal outcomes.
Unique to humans, $\mathrm{PE}$ is a multi-organ disease whose origin is not known. Symptoms present themselves in a normotensive woman after the twentieth week of gestation. However, pre-eclampsia can occur in normotensive patients with trophoblastic disease for example, a molar pregnancy prior to the twentieth week [5]. In addition, the risk of developing preeclampsia is greater in women with pre-existing conditions such as chronic hypertension, diabetes, anti-phospholipid syndrome, and collagen vascular disease. 
Preeclampsia can be described as mild or severe. Mild PE is characterized by a sustained systolic blood pressure equal to or greater than $140 \mathrm{mmHg}$, a diastolic blood pressure equal to or greater than $90 \mathrm{mmHg}$, and proteinuria of 300 $\mathrm{mg}$ in a 24-h urine collection. PE is considered severe when systolic pressure is $160 \mathrm{mmHg}$ or higher, diastolic pressure is $110 \mathrm{mmHg}$ or higher, or there is proteinuria of at least $5 \mathrm{~g}$ in a 24-h urine collection. Other manifestations of severe PE are oliguria (urine output $<400 \mathrm{ml}$ in $24 \mathrm{~h}$ ), cerebral or visual disturbances, pulmonary oedema, thrombocytopenia, and impaired liver function [6].

It is estimated that preeclampsia affects $2-8 \%$ of pregnancies worldwide and is associated with $10-15 \%$ of direct maternal deaths [7]. A secondary analysis of World Health Organisation (WHO) multi-country survey data found a global prevalence of preeclampsia and eclampsia of $4.6 \%$ and $1.4 \%$, respectively, with combined Preeclampsia/Eclampsia prevalence of $4 \%$ [8].

In Zambia, a health facility-based study in Lusaka estimated PE prevalence at $18.9 \%$ [9]. Another study conducted at the University Teaching Hospital (UTH) in Lusaka reported preeclampsia prevalence at $12 \%$ [10].

According to a recent government assessment of the current 398 maternal deaths per 100,000 live births at the national level in Zambia, $18 \%$ are directly attributed to $\mathrm{PE} / \mathrm{E}$, second only to haemorrhage at $28 \%$ [11]. Presently, routine facility data at the UTH for Women and Newborns suggests PE contributes to about $30 \%$ to maternal mortality within the hospital.

Generally, all evidence points to an increasing trend of pregnant women presenting with $\mathrm{PE}$ over the years; this trend also suggests that the Zambian health system may be struggling in its response to the maternal health problem because there has been little understanding of the health system and maternal drivers of PE in the country.
Therefore, the study aims to determine maternal predictors and health system factors of preeclampsia amongst pregnant women in Lusaka, Zambia.

\section{Methods}

This was a retrospective cohort study done by review of antenatal health records of pregnant women from January 2020 to December 2020. Seven hundred and seventh pregnant women attending ANC from five health facilities were selected using two-staged sampling techniques. The health facilities were selected using a simple random, while pregnant women were selected using consecutive sampling.

Health System factors were also assessed using the Health Facility Assessments (HFAs) checklist.

Data were analysed using SPSS. Health facility data were also analysed to assess providers' knowledge in diagnosing and managing pre-eclampsia/eclampsia and facility readiness for preeclampsia.

The PE prevalence between the two groups was determined, Univariate analysis was performed on all the demographic and risk factors variables. All data were presented in proportion and percent. Bivariate analysis was performed to estimate the relative risk of having $\mathrm{PE}$ and to measure the association between maternal factors, health system factors, and PE. The Chi-square test was also used to measure for the association. Binary logistic regression was performed to adjust for confounders. All were done $p$-value $<0.5$ and $95 \%$ confidence interval.

\section{Results}

The study consisted of 770 women attending antenatal at five health facilities in Lusaka. The respondents' ages ranged from 18-40years with a mean of 27.09 years with $\mathrm{SD} \pm 5.1$. The majority of the respondents were aged from 25 to 32,344 (45\%), 250 (82\%) were married, 346 $(45 \%)$ had secondary school as their academic status, and 293 (38\%) had parity of 2. (Table 1). 
Table 1. Demographic Characteristics of Pregnant Women attending Antenatal Clinic in Lusaka, 2020

\begin{tabular}{|l|l|}
\hline Demographic Characteristics & Frequency (Percent) \\
\hline Age group (years) & $265(34)$ \\
\hline $18-24$ & $344(45)$ \\
\hline $25-32$ & $151(20)$ \\
\hline $33-40$ & $10(1)$ \\
\hline NO RESPONSE & $250(82.0)$ \\
\hline Marital Status & $49(16.07)$ \\
\hline Married & $6(1.97)$ \\
\hline Single/Divorced/widow & $117(15.1)$ \\
\hline Co-habiting & $346(45)$ \\
\hline Highest Academic Status & $279(36.2)$ \\
\hline Primary & \\
\hline Secondary & $261(34)$ \\
\hline Tertiary & $293(38)$ \\
\hline Parity & $215(28)$ \\
\hline 1 & $334(43.4)$ \\
\hline 2 & $436(56.6)$ \\
\hline $3<$ & \\
\hline Preeclampsia & \\
\hline Preeclampsia & \\
\hline No pre-eclampsia &
\end{tabular}

Most of the participants had never heard of preeclampsia before 427 (54\%). The highest proportion of correct responses regarding the signs/symptoms of PE were high blood pressure during pregnancy $276(36 \%)$ followed by persistent headache $49(6.3 \%)$, the highest risk factor was said to be multiple births 205 (26.6\%) and then followed by unhealthy lifestyle 201 (26.1\%). (Table 2).

Table 2. Knowledge on Preeclampsia amongst Pregnant Women in Lusaka

\begin{tabular}{|l|l|l|}
\hline Have you heard of PE? & Frequency (n) & Percentage (\%) \\
\hline Yes & 347 & 45 \\
\hline No & 423 & 54 \\
\hline What are some of the signs/symptoms of PE? & \multicolumn{2}{|l|}{} \\
\hline High blood pressure (during pregnancy) & 276 & 36 \\
\hline Persistent headache & 49 & 6.3 \\
\hline Oedema & 26 & 3.3 \\
\hline Blurred vision & 31 & 4.0 \\
\hline Chest pain & 89 & 11.5 \\
\hline Abdominal pain & 165 & 21.4 \\
\hline Nausea and vomiting & 115 & 15 \\
\hline Back pain & 19 & 2.4 \\
\hline What are some of the risk factors for PE? & \\
\hline Family history of PE & 177 & 23 \\
\hline Having prior PE & 103 & 13.3 \\
\hline
\end{tabular}




\begin{tabular}{|l|l|l|}
\hline Obesity & 31 & 4 \\
\hline Diabetes & 53 & 6.8 \\
\hline Unhealthy lifestyle & 201 & 26.1 \\
\hline Multiple births & 205 & 26.6 \\
\hline What are some of the complications of PE? & \multicolumn{2}{|l|}{} \\
\hline Maternal death & 311 & 40.3 \\
\hline Fetal death & 203 & 26.3 \\
\hline Heart disease & 120 & 15.1 \\
\hline Kidney dysfunction & 96 & 12.4 \\
\hline Dietary factors & 40 & 5.9 \\
\hline
\end{tabular}

Out of the 770 women, $238(30.7 \%)$ were nulliparous women, 651 (84.5\%) admitted having hypertension during pregnancy. 177 (23\%) admitted having experienced PE before, $400(52 \%)$ stated not having PE before, and 192 $(25 \%)$ had no idea. In terms of having a history in the family majority $385(50.1 \%)$ stated that there was no history at all. With regards to fruit, vegetable, and coffee intake the majority stated once per week 350 (45\%), daily 537 (70\%) and $342(44 \%)$ respectively. Most of the women, 481 (62\%) admitted having undergone nutritional counselling during antenatal visits. (Table 3).

Table 3. Maternal Predictors of Preeclampsia amongst Pregnant Women attending Antenatal Clinic in Lusaka, 2020

\begin{tabular}{|l|l|l|}
\hline First pregnancy & Frequency (n) & Percentage (\%) \\
\hline YES & 238 & 30.7 \\
\hline NO & 532 & 69.2 \\
\hline Hypertension in Pregnancy \\
\hline Yes & 651 & 84.5 \\
\hline No & 119 & 15.5 \\
\hline Experienced PE before & 177 & 23 \\
\hline YES & 400 & 52 \\
\hline NO & 192 & 25 \\
\hline I Don't know & 51 & 6.6 \\
\hline Family history of PE & 50.1 \\
\hline Yes & 385 & 43.3 \\
\hline No & 334 & 22 \\
\hline I don't know & 45 \\
\hline Fruit intake & 172 & 33 \\
\hline Daily & 350 & 70 \\
\hline Once per week & 248 & 14 \\
\hline No & 16 \\
\hline Vegetable intake \\
\hline Daily & 537 & 44 \\
\hline Once per week & 110 & \\
\hline No & 43 & \\
\hline Coffee intake & 342 & \\
\hline Daily & \\
\hline
\end{tabular}




\begin{tabular}{|l|l|l|}
\hline Once per week & 305 & 40 \\
\hline No & 123 & 16 \\
\hline \multicolumn{2}{|l|}{ Nutritional counselling } \\
\hline Yes & 481 & 62 \\
\hline No & 289 & 38 \\
\hline
\end{tabular}

Of the 41 interviewed health personnel, all $(100 \%)$ agreed they checked for blood pressure in assessment for preeclampsia. The lowest response $8(20 \%)$ was recorded in assessment of consciousness as most did not respond to it. Urine assessment 38 (93\%) was also a frequent parameter assessed in preeclampsia checks by health personnel. (Table 4).

Table 4. Health System Factors associated to Preeclampsia amongst Pregnant Women in Lusaka, 2020

\begin{tabular}{|l|l|l|}
\hline Knowledge parameter assessed through the test case & Frequency (n) & Percentage (\%) \\
\hline Initial assessment for pre-eclampsia & 41 & 100 \\
\hline Check blood pressure & 8 & 20 \\
\hline Assess consciousness & 35 & 85 \\
\hline Measure fetal heart rate & 38 & 93 \\
\hline Assess urine for protein & 10 & 26 \\
\hline Diagnosis and management of severe pre-eclampsia & 6 & 14 \\
\hline Diagnose severe pre-eclampsia & 6 & 18 \\
\hline Administer magnesium sulphate & 7 & 42 \\
\hline Administer anti-hypertensive drugs if diastolic BP > $110 \mathrm{~mm} \mathrm{Hg}$ & 17 & \\
\hline Immediately refer to higher facility & 17 & \\
\hline
\end{tabular}

Out of the 334 pregnant women that developed PE, the age group of 30-34 had the highest number 73 (21.8\%), $202(60.4 \%)$ had attained secondary education, 21 (43.9\%) were either single, divorced, or widowed. 118 (54.8 $\%$ ) had a parity of 3 or more. (Table 5).

Table 5. Demographic Characteristics associated to Pre-eclampsia amongst Pregnant Women in Lusaka, 2020

\begin{tabular}{|l|l|l|l|}
\hline \multirow{2}{*}{ Factors } & Preeclampsia & No Preeclampsia & P-value \\
\cline { 2 - 3 } \multicolumn{2}{|l|}{$\mathbf{n = 3 3 4}$ (percent) } & n= 436 (percent) & \\
\hline Age & 0 & 0 & P=<0.001 \\
\hline$<15$ & $36(10.7)$ & $63(14.4)$ & \\
\hline $15-19$ & $70(20.9)$ & $114(26.1)$ & 0.102 \\
\hline $20-24$ & $53(15.86)$ & $104(24)$ & 0.067 \\
\hline $25-29$ & $73(21.8)$ & $74(17)$ & 0.072 \\
\hline $30-34$ & $64(19.2)$ & $68(15.6)$ & 0.015 \\
\hline $35-39$ & $38(11.3)$ & $13(2.9)$ & 0.056 \\
\hline$>39$ & \multicolumn{5}{|l}{} & 0.087 \\
\hline Education & $9(2.7)$ & $15(3.5)$ & P=<0.001 \\
\hline Non & $97(29.04)$ & $145(33.3)$ & 0.011 \\
\hline Primary & $202(60.4)$ & $237(54.3)$ & 0.067 \\
\hline Secondary & $26(7.7)$ & $39(8.9)$ & 0.099 \\
\hline Tertiary & & & 0.012 \\
\hline Marital Status & & \\
\hline
\end{tabular}




\begin{tabular}{|l|l|l|l|}
\hline Married (250) & $89(36.6)$ & $161(64.4)$ & 0.111 \\
\hline Single/Divorced/widow (49) & $21(43.9)$ & $28(57.1)$ & 0.023 \\
\hline Co-habiting (6) & $1(16.7)$ & $5(83.3)$ & 0.002 \\
\hline Parity & $106(40.6)$ & $155(59.4)$ & 0.157 \\
\hline $1(261)$ & $131(44.7)$ & $162(55.29)$ & 0.146 \\
\hline $2(293)$ & $118(54.8)$ & $97(45.1)$ & 0.013 \\
\hline $3<(215)$
\end{tabular}

Women who developed PE in the first pregnancy were at risk of developing PE (RR: 4.4), this includes those who had a high intake of energy foods (RR: 1.17), whilst having knowledge on PE (RR: 0.6), eating of foods like fibre and calcium were protective of $\mathrm{PE}$ respectively. (RR: 0.46 and 0.88 ). (Table 6a).

Table 6a. Maternal Predictors associated to Pre-eclampsia amongst Pregnant Women in Lusaka, 2020

\begin{tabular}{|c|c|c|c|c|}
\hline \multirow[t]{2}{*}{ First pregnancy } & Preeclampsia & No Preeclampsia & \multirow[t]{2}{*}{ AOR $(95 \%$, CI) } & \multirow[t]{2}{*}{ Relative risk } \\
\hline & $\mathrm{n}=\mathbf{3 3 4}$ (percent) & $n=436$ (percent) & & \\
\hline Yes & $38(11.3)$ & $217(49.7)$ & $0.34(0.33,1.17) *$ & 4.4 \\
\hline No & $292(87.4)$ & $223(51.1)$ & $0.13(0.20,2.31) *$ & 0.58 \\
\hline \multicolumn{5}{|c|}{ Knowledge on preeclampsia/eclampsia } \\
\hline Yes & $123(36.8)$ & $98(22.4)$ & $0.71(0.20,3.37) *$ & 0.60 \\
\hline No & $271(81.1)$ & $278(63.7)$ & $0.94(0.20,4.32) *$ & 0.78 \\
\hline \multicolumn{5}{|l|}{ Family history of PE } \\
\hline Yes & $195(58.3)$ & $173(39.6)$ & $0.52(0.13,1.17) *$ & 0.68 \\
\hline No & $91(27.2)$ & $278(63.7)$ & $0.71(0.23,3.22) *$ & 2.34 \\
\hline I don't know & $22(6.6)$ & $11(2.5)$ & $0.94(0.20,1.32) *$ & 0.37 \\
\hline \multicolumn{5}{|l|}{ Food intake } \\
\hline Energy (kcal/day) & $76(22.7)$ & $116(26.6)$ & $0.94(0.20,4.32) *$ & 1.17 \\
\hline Carbohydrate (g/day) & $107(32)$ & $135(30.9)$ & $0.94(0.20,4.32) *$ & 0.96 \\
\hline Fiber (g/day) & $71(21.2)$ & $43(9.86)$ & $0.94(0.20,4.32) *$ & 0.46 \\
\hline Calcium (mg) & $27(8)$ & $31(7.11)$ & $0.94(0.20,4.32) *$ & 0.88 \\
\hline Protein & $53(15.8)$ & $111(25.4)$ & $0.94(0.20,4.32) *$ & 1.60 \\
\hline
\end{tabular}

Drinking coffee daily was found not to be associated with preeclampsia in bivariate analysis (COR: 3.26, 95\% CI 0.42, 25.36). Receiving nutritional counselling during antenatal care follow-up was found to be protective for preeclampsia in the multivariable analysis as opposed to the bivariate analysis (AOR: 0.17, 95\% CI 0.05, 0.6) (Table 6b).
At least once a week during pregnancy, fruit and vegetable intake was a protective factor against preeclampsia (RR: 0.4 and RR: 0.7. Comparing to women who didn't eat fruit or vegetables, women who ate fruit or vegetable daily were less at risk of developing preeclampsia (AOR: 0.94, 95\% CI 0.20, 4.32) and (AOR: $0.95,95 \%$ CI 0.01, 0.71) respectively (Table 6b).

Table 6b. Maternal Predictors associated to Pre-eclampsia amongst Pregnant Women in Lusaka, 2020

\begin{tabular}{|l|l|l|l|l|}
\hline Fruit intake & $202(60.4)$ & $46(10.5)$ & 1 & 5.75 \\
\hline No & $51(15.2)$ & $121(27.7)$ & $0.94(0.20,4.32) *$ & 0.55 \\
\hline Daily & $81(24.2)$ & $269(61.6)$ & $0.23(0.06,0.91) *$ & 0.4 \\
\hline At least once per week & & 1 & 3.4 \\
\hline Vegetable intake & $31(9.2)$ & $12(2.7)$ & 1 \\
\hline No
\end{tabular}




\begin{tabular}{|l|l|l|l|l|}
\hline Daily & $236(71)$ & $301(69.0)$ & $0.95(0.01,0.71)^{*}$ & 1.0 \\
\hline At least once per week & $67(20)$ & $123(28.2)$ & $0.25(0.05,1.37) *$ & 0.70 \\
\hline Coffee intake & $50(15)$ & $73(21.8)$ & 1 & \\
\hline No & $148(44.3)$ & $194(44.5)$ & $3.26(0.42,25.36)$ & 0.99 \\
\hline Daily & $137(41.0)$ & $169(39)$ & $5.09(0.93,27.97)$ & 1.05 \\
\hline At least once per week & Nutritional counseling during ANC & 1 & 0.44 \\
\hline No & $73(21.8)$ & $216(49.5)$ & $0.17(0.05,0.6) *$ & 1.54 \\
\hline Yes & $261(78.1)$ & $220(50.4)$ & & \\
\hline
\end{tabular}

In relation to the diagnosis and management of severe pre-eclampsia, anti-hypertensive drugs, and magnesium sulphate respectively; 14\% (95\% C.I, 11.1-17.6) would record inputsoutputs; and $18 \%$ (95\% C.I, 14.7-21.9) would monitor for the toxicity of magnesium sulphate as a part of follow-up care for eclampsia. In comparison with higher facilities, public health facilities performed poorly across many knowledge parameters, but significant differences were observed in the administration of magnesium sulphate for severe preeclampsia and administration of oxygen $(\mathrm{p}=0.001)$, and use of anti-hypertensive for eclampsia ( $\mathrm{p}<$ 0.05). Compared to doctors and specialists, staff nurses had poorer knowledge related to the management of pre-eclampsia, and most of the differences were statistically highly significant $(\mathrm{p}<0.001)$ (Table 7).

Table 7. Health System Factors associated to Preeclampsia amongst Pregnant Women in Lusaka, 2020

\begin{tabular}{|c|c|c|c|c|c|c|}
\hline $\begin{array}{l}\text { Knowledge parameter } \\
\text { assessed through the test case }\end{array}$ & Total (41) & $\begin{array}{l}\text { CI [95\% Conf. } \\
\text { Interval] }\end{array}$ & $\begin{array}{l}\text { Specialists } \\
(14)\end{array}$ & $\begin{array}{l}\text { Doctors } \\
(6)\end{array}$ & $\begin{array}{l}\text { Nurse/ANM } \\
(21) \\
\end{array}$ & P Value* \\
\hline \multicolumn{7}{|c|}{ Initial assessment for preeclampsia } \\
\hline Check blood pressure & $41(100 \%)$ & & 14 & 6 & 21 & $\mathrm{P}<0.021$ \\
\hline Assess consciousness & $8(20 \%)$ & $16.7-20.9$ & 1 & 6 & 1 & $\mathrm{p}<0.011$ \\
\hline Measure fetal heart rate & $35(85 \%)$ & $11.8-15.0$ & 14 & 0 & 21 & $\mathrm{p}=0.002$ \\
\hline Assess urine for protein & $38(93)$ & $11.3-13.1$ & 14 & 6 & 18 & $\mathrm{P}<0.023$ \\
\hline \multicolumn{7}{|c|}{ Diagnosis and management of severe preeclampsia } \\
\hline Diagnose severe preeclampsia & $10(26 \%)$ & $13.3-16.1$ & 3 & 4 & 2 & $\mathrm{P}<0.001$ \\
\hline $\begin{array}{l}\text { Administer magnesium } \\
\text { sulphate }\end{array}$ & $6(14 \%)$ & $11.1-17.6$ & 2 & 3 & 1 & $\mathrm{p}<0.001$ \\
\hline $\begin{array}{l}\text { Administer anti-hypertensive } \\
\text { drugs if diastolic } \mathrm{BP}>110 \mathrm{~mm} \\
\mathrm{Hg}\end{array}$ & $7(18 \%)$ & $14.7-21.9$ & 2 & 4 & 1 & $\mathrm{p}=0.001$ \\
\hline $\begin{array}{l}\text { Immediately refer to higher } \\
\text { facility }\end{array}$ & $17(42 \%)$ & $10.8-17.0$ & 4 & 4 & 9 & $\mathrm{P}<0.033$ \\
\hline
\end{tabular}

The facility audits revealed gaps in the availability of human resources and in the availability of certain key equipment, drugs, and supplies.

Multivariate analysis revealed that age of the woman $(\mathrm{aOR}=0.326,95 \%$ CI: 0.0024-0.8231), education $\mathrm{aOR}=0.128$, 95\% CI: $0.00121-$ 0.0323 ) and a good nutritional diet $\mathrm{aOR}=0.109$, 95\% CI: $0.0393-0.4639)$ by participants were associated with low effects or are protective of preeclampsia. (Table 8). 
Table 8. Multivariate analysis of Statistically Significant Factors in Relation to PE amongst Pregnant Women in Lusaka, 2020

\begin{tabular}{|l|l|l|l|}
\hline Variables & Odds Ratio & 95\% Conf. Interval & P-value \\
\hline Age & 0.326 & $0.0024-0.8231$ & 0.113 \\
\hline Nutrition & 0.109 & $0.0393-0.4639$ & 0.421 \\
\hline Education & 0.128 & $0.0121-0.0325$ & 0.330 \\
\hline Parity & 0.126 & $0.0111-0.611$ & 0.011 \\
\hline
\end{tabular}

\section{Discussion}

The current study results show that women with preeclampsia was particularly low among women with tertiary education and preeclampsia was mostly among women who had reached the secondary level of education with a percentage of $57.3 \%$, and these findings are contrary to a study done in Southern Ethiopia which found that mothers who attended primary education had a $92.9 \%$ reduced risk of getting preeclampsia than the mothers who cannot read and write [12] and this result is supported by a study done in the Gaza Strip [13] and Jakarta [14] This could be explained by uneducated mothers having reduced access to early prevention and control mechanisms; healthy nutrition, avoiding sedentary life, and prevention of overweight and obesity [15] which are identified as risk factors for preeclampsia. The study done in Jakarta also showed that mothers who have low educational levels had $86 \%$ higher risk of preeclampsia, while middle education level had a $72 \%$ higher risk of preeclampsia than those who have higher educational level [14].

On marital status, single, divorced, and widowed women were found to be more at risk of developing preeclampsia during pregnancy. Similar to a study on the management of PE in North East Ethiopia, it revealed that marital status is one of the factors to the development of PE. Single women have higher odds of developing PE than married women. This may be attributed to the possibility of low preconception seminal fluid exposure among unmarried women and the stress of managing a pregnancy alone [16]. Being primi gravida, that is, being pregnant for the first time, is a risk factor, and it has been known to be a major causal factor according to the studies done in Africa. The researchers attributed this finding to the maternal first exposure to trophoblast as being of foetal origin [17], contradicting what the study revealed, stating women with parity of more than three are more at risk. It is likely that parity increases with age.

The study has also revealed that most women had no knowledge on PE (88.6\%, mean score $=55.5 \pm 4.3$, similarly, earlier studies have also reported low knowledge of PE among women, for instance, a study in the US reported a $43.3 \%$ knowledge of PE among women, with only $14 \%$ being able to provide the information that accurately defines the syndrome [18]. In Malaysia, a study by Teng and Keng found only $18.4 \%$ of women to have adequate knowledge of PE [19]. Evidence indicates that adequate understanding of a disorder contributes to its prevention; control, and management because patients' knowledge regarding a disease positively influenced patient compliance to treatment and help abate complications associated with the disease [20].

On awareness of Preeclampsia by pregnant women, chronic diseases such as obesity, hypertension, and diabetes were listed as being risk factors of developing preeclampsia.

Having preeclampsia in a previous pregnancy was significantly associated with developing preeclampsia, and one of the major risk factors for pre-eclampsia has been a history of preeclampsia in the previous pregnancy and in line with this, a study by Ramesh and others established a relation between these two factors 
and strong association with an odds ratio of 58.5 was found [21]. Other studies conducted in Iran, Egypt, and Addis Ababa [22, 23, 24] support this association. This might be due to the fact that the presence of a soluble substance, which is a circulating antiangiogenic molecule of placental origin, plays a crucial role in pre-eclampsia by antagonizing placental growth factor and vascular endothelial growth factor signalling in the maternal vasculature.

The study also revealed that fruit and vegetable intake during pregnancy was protective of preeclampsia as compared to women who ate too much high energy foods and did not eat fruits or vegetables, which is in line with the findings from the Tigray region in Ethiopia were mothers who consumed less fruits in their diets were at higher risk of developing hypertensive disorders of pregnancy [25], and these findings are also similar to those done in Egypt [26] and Norway [27]. This could be attributed to the fact that fruits are rich in micronutrients, and many of the vitamins and minerals play an antioxidant role which could in turn help in the prevention of hypertensive disorders of pregnancy.

Drinking coffee at least once per week was associated with preeclampsia, and this is in conformity with a study in Bahrdar, Ethiopia, which showed that mothers who reported to have taken coffee during pregnancy had higher odds of developing preeclampsia [28]. However, another study in Rotterdam, the Netherlands, reported the substantial protection of coffee against the development of pregnancy-induced hypertension [29].

The competency assessments revealed knowledge gaps in relation to the diagnosis and management of pre-eclampsia. While health workers at level one clinics had the poorest knowledge scores, health workers at the higherlevel public also had significant knowledge gaps. This finding is quite different from the research carried out on Community Health Workers' (CHW) knowledge and practice in relation to pre-eclampsia in Ogun State, Nigeria, and Calabar [30, 31]. The study reported that the CHWs had average knowledge of pre-eclampsia. Another study on skilled birth attendant competencies in four developed countries reported that $80 \%$ of skilled birth attendants had high knowledge of pre-eclampsia [32]. A similar result was recorded in a study carried out in Northern Karnataka, India, on the assessment of facility readiness and provider preparedness for dealing with postpartum haemorrhage and preeclampsia in public and private health facilities. The study found out that the majority of respondents had high knowledge on preeclampsia, and there was a significant association between respondent knowledge of pre-eclampsia and years of experience. This may be because expertise improves with years of experience [33].

The study found that of the three types of providers (doctors, nurses, and specialists), the staff nurses had the most severe knowledge gaps this is somehow in line with a study conducted in Nigeria were knowledge was higher amongst doctors compared with "lower cadre" health workers (examples cited in the included paper include associate nurses, community health workers) [34] and this could be attributed to the nature of educational training done by doctors compared to other health workers.

\section{Conclusion}

This study revealed that the maternal predictors of preeclampsia amongst pregnant women in Lusaka, Zambia, included not having a high level of education, having preeclampsia in the previous pregnancy, being single, divorced or widowed, and having parity of three more. Protective factors of preeclampsia include daily vegetable intake, fruit intake, and nutritional counselling during antenatal care. Lack of awareness of preeclampsia amongst pregnant women is also a factor.

Health system factors such as checking for consciousness by health personnel as an initial assessment for preeclampsia and the diagnosis and management of severe preeclampsia were 
not done as there were knowledge gaps amongst the health workers in the facilities.

Therefore, health workers dealing with maternal health units of health facilities should emphasize the risk factors, symptoms, prevention, and management for preeclampsia to pregnant and postnatal mothers during their health talks in the health facilities during their routine antenatal visits. These messages should also be extended to other pregnant and postnatal mothers in the communities through health education talks.

There is also need to introduce refresher training courses in the diagnosis, prevention and management of preeclampsia among all health cadres dealing with pregnant women across all health facilities to tackle the existing knowledge gaps.

\section{Ethics Approval and Consent to Participate}

The Study was approved University of Lusaka School of Medicine Ethics committee and the National Health Research Authority.

Approval to conduct the study was obtained from the five health facilities, and all participants gave consent after receiving detailed information about the study. Confidentiality was maintained by avoiding specific personal identifiers in the study instrument.

\section{References}

[1] Vousden N, Lawley E, Seed PT, et al. Incidence of eclampsia and related complications across 10 low- and middle-resource geographical regions: Secondary analysis of a cluster randomized controlled trial. PLoS Med. 2019; 16(3): e1002775. https://doi.org/10.1371/journal.pmed.1002775.

[2] World Health Organization. (2015) Trends in maternal mortality: 1990 to 2015. Estimates by WHO, UNICEF, UNFPA, The World Bank, and the United Nations Population Division. Geneva: World Health Organization; 2015 [cited 2019 Mar 6]. Available

from:

\section{Consent for Publication}

Not applicable

\section{Availability of Data and Materials}

All the data associated with this work is available from the corresponding author on reasonable request.

\section{Competing Interests}

The authors declare that they have no competing interests.

\section{Funding}

The authors did not receive any funding support for this work.

\section{Authors' Contributions}

PM conceived and designed the study, collected data, and analysed it. HM discussed the results. UAO reviewed the Manuscript All authors read and approved the final version for submission.

\section{Acknowledgements}

We acknowledge the health staffs from the five health facilities who generally made themselves available and contributed to this study. Our appreciation also goes to the research assistants and the study participants who agreed to participate in the study.

http://apps.who.int/iris/bitstream/10665/194254/1/97 89241565141_eng.pdf? ua=1.

[3] Say L, Chou D, Gemmill A, et al. (2014) Global causes of maternal death: a WHO systematic analysis. Lancet Glob Health. 2014; 2(6): e323-33.

[4] World Health Organization. (2011) WHO recommendations for Prevention and treatment of preeclampsia and eclampsia. Geneva: World Health Organization. 2011.

[5] Ness R B and Roberts J M (1996) Heterogeneous causes constituting the single syndrome of preeclampsia: a hypothesis and its implications, AmJ Obstet Gynecol Nov; 175(5):1365-70. 
[6] Ramanathan J and Kelly B (2003) Pre-eclampsia: fluids, drugs, and anesthetic management, Anesthesiol Clin North Am, 2003 Mar; 21(1):145-63. [7] Duley L (2009). The Global Impact of Preeclampsia and Eclampsia. Semin Perinatol. Jun. 2009; 33(3):130-7. http://dspace.unza.zm:8080/xmlui/handle/12345678 9/3145? show=full.

[8] Abalos E, Cuesta C, Grosso AL, Chou D, Say L. (2013) Global and regional estimates of preeclampsia and eclampsia: a systematic review. Eur J Obstet Gynecol Reprod Biol. 2013; 170(1):1-7.

[9] Chowa PE, Lin C, Goma F, (2011) Prevalence of Hypertension Among Women of Child.

[10] Chisoko CE. (2013) Preeclampsia: maternal and fetal outcomes according to symptomatology and proteinuria at University Teaching Hospital, Lusaka. University of Zambia. 2013.

[11] Ministry of Community Development, Mother and Child Health and Ministry of Health. Zambia National Emergency Obstetric and Newborn (EmONC) Needs Assessment 2014-15, Preliminary report, October 22 2015, Lusaka, Zambia.

[12] Mareg, M, Molla, A. Berhanu, M, Z, Hagos, B. Determinants of Preeclampsia among Pregnant Mothers Attending Antenatal Care (ANC) and Delivery Service in Gedeo Zone, Southern Ethiopia: Case Control-Study. International journal of women's health. 2020: 567-575.

[13] Samar E. Case-control study of risk factors associated with preeclampsia in the Gaza strip. J Med Sci. 2015; 6(9):229-233.

[14] Van Katwijk C, Peeters LL. Clinical aspects of pregnancy after the age of 35 years: a review of the literature. Hum Reprod Update. 1998; 4(2):185-194. doi:10.1093/humupd/4.2.185.

[15] Ennazhiyil SV, Valsan SM, Rajeev AV, Srinivasan C, Kunnath RP. The socio-demographic determinants of gestational diabetes mellitus among postnatal women from Palakkad district, Kerala: comparative study. Int J Community Med Public Health. 2019; 6(6):2449.

[16] Tessema A G, Tekeste A, Ayele A T (2015) Preeclampsia and associated factors among pregnant women attending antenatal care in Dessie referral hospital, Northeast Ethiopia: a hospital-based study, BMC Pregnancy and Childbirth (2015) 15:73.

[17]Duckitt K, Harrington D (2005) Risk factors for pre-eclampsia at antenatal booking: systematic review of controlled studies, BMJ (online) 330(7491):565 DOI: 10.1136/bmj.38380.674340.E0. [18]18. You W, B, Wolf M, Bailey S, C. Factors associated with patient understanding of preeclampsia. Hypertension Pregnancy. 2012; 31(3):341-9.

[19]Teng S, P, Keng S, L. Knowledge of preeclampsia among antenatal women in a tertiary referral teaching hospital. Malaysia Journalin Nursing. 2016; 7:8-13.

[20] Adams R, J. Improving health outcomes with better patient understanding and education. Risk manage Health Policy. 2010; 3:61.

[21] Ramesh, K. Ghandi, S, Rao, V (2014) SocioDemographic and Other Risk Factors of Preeclampsia at a Tertiary Care Hospital, Karnataka: Case Control Study. Journal of clinical and diagnostic research 8 (9): JC01-JC04.

[22] Kashanian M, Baradaran HR, Bahasadri S, Alimohammadi R. Risk factors for pre-eclampsia: a study in Tehran, Iran. Arch Iran Med. 2011; 4(6):412415.

[23] El-Moselhy EA, Khalifa HO, Amer SM, Mohammad KI, El-AalHMA. Risk factors and impacts of pre-eclampsia: an epidemiological study among pregnant mothers in Cairo, Egypt. J Am Sci. 2011; 7(5):311-323.

[24] Mohammed E, Agero G, Ali E. Pre-Eclampsia Risk Factors Among Pregnant Women Attending in Four Public Health Facilities of Addis Ababa City. Ethiopian Journal of Reproductive Health. 2017; 9:45-59.

[25] Kahsey, H.B, Gashe, F, Ayele, W.M (2018) Risk factors for hypertensive disorders of pregnancy among mothers in Tigray region, Ethiopia: matched case-control study. Springer link journal.

[26]El-Moselhy EA, Khalifa HO, Soliman M, Mohammad KI, Abd El-Aal HM. Risk factors and impacts of pre-eclampsia: an epidemiological study among pregnant mothers in Cairo Egypt. Journal of American Science. 2011; 7(5):311-23. 
[27]Brantsæter AL, Haugen M, Samuelsenet SO, Torjusen H, Trogstad L, Alexander J. A dietary pattern characterized by high intake of vegetables, fruits, and vegetable oils is associated with reduced risk of preeclampsia in nulliparous pregnant Norwegian women. J Nutr. 2009; 139(6):1162-8.

[28] Endeshaw M, Ambaw F, Aragaw A, Ayalew A. Effect of maternal nutrition and dietary habits on preeclampsia: a case-control study. International Journal of Clinical Medicine. 5(21):1405.

[29] Van der Hoeven T, Browne JL, Uiterwaal C, et al. Antenatal coffee and tea consumption and the effect on birth outcome and hypertensive pregnancy disorders. PLoS One. 2017; 12(5):1-12.

[30] Akeju D. O, Vidler M, Oladapo O.T, etal., CLIP Nigeria Feasibility Working Group. Community perceptions of preeclampsia and eclampsia in Ogun state, Nigeria: a qualitative study. Reproductive Health. 2016; 13 Supplement 1:57.

[31]James E. O, Mgbekem M. A, Edem O. A. Knowledge, attitude and preventive practices towards pregnancy induced hypertension among pregnant women in general hospital, Calabar, Cross River State, Nigeria. Pakistan Journal of Social Sciences. 2009; 6(1):1-5.

[32] Harvey SA, Ayabaca P, Bucagu M, Djibrina S, Edson WN, Gbangbade S. Skilled birth attendant competence: An initial assessment in four countries, and implications for the Safe Motherhood movement. International Journal of Gynaecology and Obstetrics. 2004; 87(2):203-210.

[33] Ayanna K, Mony P, Ramesh BM, Thomas A, Gaikwad A, Mohan HL, et al. Assessment of facility readiness and provider preparedness for dealing with postpartum haemorrhage and preeclampsia/eclampsia in public and private health facilities of northern Karnataka, India: a crosssectional study. BMC Pregnancy Childbirth. 2014; 14(1):304.

[34] Adekanle DA, Adeyemi AS, Olowookere SA, Akinleye CA. Health workers' knowledge on future vascular disease risk in women with pre-eclampsia in south western Nigeria. BMC Research Notes. (2015) 8:576. 